\section{A SENSODYNE SUCCESS STORY}

The winner of the 2012 toothpaste Product of the Year award* just keeps on growing! The Sensodyne

Repair \& Protect range now makes up over 28\% of the UK sensitive toothpaste market**. Growth

has been rapid - recent data show that Sensodyne Repair \& Protect has grown by over $50 \%$ in the

last year*

Sensodyne Repair \& Protect - now also available in Whitening and Extra Fresh variants - contains NovaMin, which builds a layer over exposed dentine relieve dentine hypersensitivity. ${ }^{2-4}$ For more information on dentine hypersensitivity and Sensodyne Repair \& Protect, or to request trial-sized product packs for your practice, visit www. gsk-dental professionals.co.uk.

*Winner Toothpaste Category. Survey of 9,063 people by TNS

*value share

Nielsen. Value sales data, all outlets. 4 weeks WE 22/09/12.

Du M Q, Bian Z, Jiang $\mathrm{H}$ et al. Clinical evaluation of a dentifrice containing calcium sodium phosphosilicate (novamin) for the treatment of dentin hypersensitivity. Am J Dent 2008; 21: 210-214.

Pradeep A R, Sharma A. Comparison of clinical efficacy of a dentifrice containing calcium sodium phosphosilicate to a dentifrice

containing potassium nitrate and to a placebo on dentinal hypersensitivity: a randomized clinical trial. J Periodontol 201 0;81:

Salian S et al A randomized controlled clinical study evaluating the efficacy of two desensitizing dentifrices 1 Clin Dent 2010 $21: 82-87$

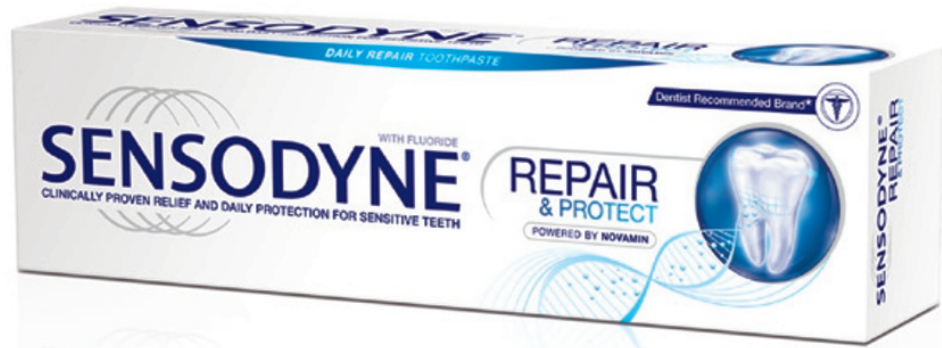

\section{SHOW YOUR HANDS YOU CARE}

Isn't it about time you showed your hands and wrists how much you care? With

RSI becoming all too common

in the workplace DENTSPLY has

created resin and silicone handled instruments that are ergonomically designed to offer a firm grip and a complete sense of control for a tool that is kind to your hands.

It is true that the instruments you use at work become an extension of you, so you deserve an implement of the highest distinction. Over a period of time, repeating the same procedures over and over again can leave you at risk of developing RSI. But the comfort and grip provided by DENTSPLY instruments minimise the chances of this, and provide less strain on your hands and wrists

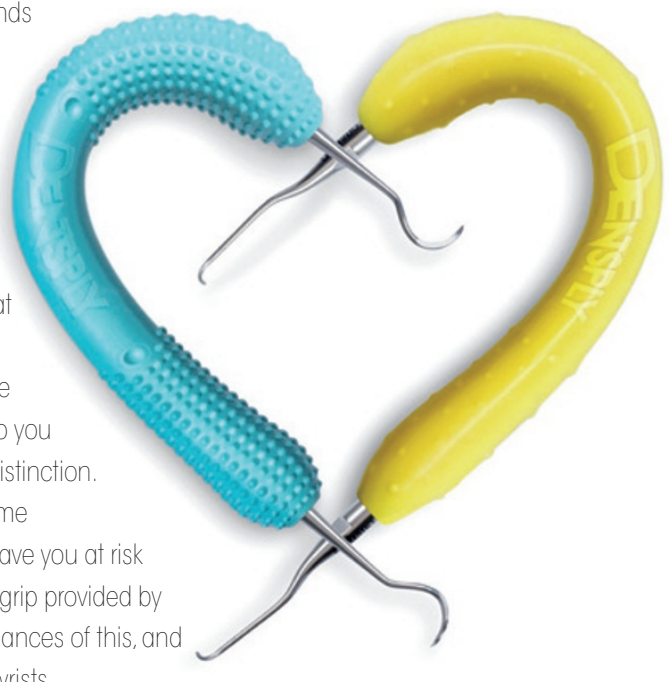

DENTSPLY silicone instruments are also cost effective as they offer interchangeable tips, meaning that, should one break, you will only need to replace the end and not the entire instrument.

Go on, treat your hands and wrists to an ergonomically designed hand instrument from DENTSPLY they'll thank you for it!

Visit www. dentsply.co.uk or call 0800072 3313. Earn rewards against purchases at www. dentsplyrewards.co.uk
EDUCATION FOR EVERY DENTAL PROFESSIONAL

Some of the most exciting learning opportunities for dental professionals can be found at cpdreview.com.

Opportunities for the dental nurse to acquire new skills are abundant, ranging from orthodontic nursing to conscious sedation and dental photography. There are also specific programmes for implant training that teach everything from initial treatment planning all the way through to managing complications and delivering remedial measures. For nurses interested in holistic health training is available in areas such as dental acupuncture and homeopathy,

For dental hygienists and therapists, a brand new course devised by the Dawson Academy UK for 2013 teaches the art of smile design principles, perfect for practitioners interested in aesthetic dentistry.

The hot topic of regenerative dentistry has now been made accessible to all, with a unique team training course introduced this year by Precious Cells International The course delivers specialist training for the whole team in the extraction and use of dental pulp in the field of regenerative medical research and treatment.

If you're looking for a new challenge and a chance to elevate your career to the next level you can find over 700 courses listed at cpdreview.com

\section{ALL DAY BAD BREATH PROTECTION}

In up to $90 \%$ of cases, bad breath is the result of oral bacteria breaking down food particles in the mouth. It's estimated that half the population suffers from some degree of bad breath (halitosis), and for many the

problem can have a huge effect on both their private and professional relationships.

CB12 is a new mouth rinse that is proven to outperform existing mouthwash solutions and deliver security from the embarrassment of bad breath for 12 hours.

CB12 contains two complementary ingredients: zinc acetate and chlorhexidine diacetate, which work together to neutralise the gaseous VSCs (volatile sulphur compounds) which cause bad breath. CB12 also contains fluoride to help protect teeth and to help patients maintain a high standard of oral health

While many 'fresh breath' products simply mask the odour of bad breath, CB12 attacks the problem at its source, neutralising the odour-causing bacteria and preventing recurrence for up to 12 hours

Suitable for nearly everyone over the age of 12,CB12 mouth rinse is available in two flavours, mint menthol and mild, to suit all patients' tastes.

For more information on CB12 visit uww.cb12.com

If you would like to promote your products or services direct to the dental industry through VITAL UPDATE telephone Stephen Brown on 02078434724. 